\title{
Thread facelift: Satisfaction rate among the patients using FACE-Q
}
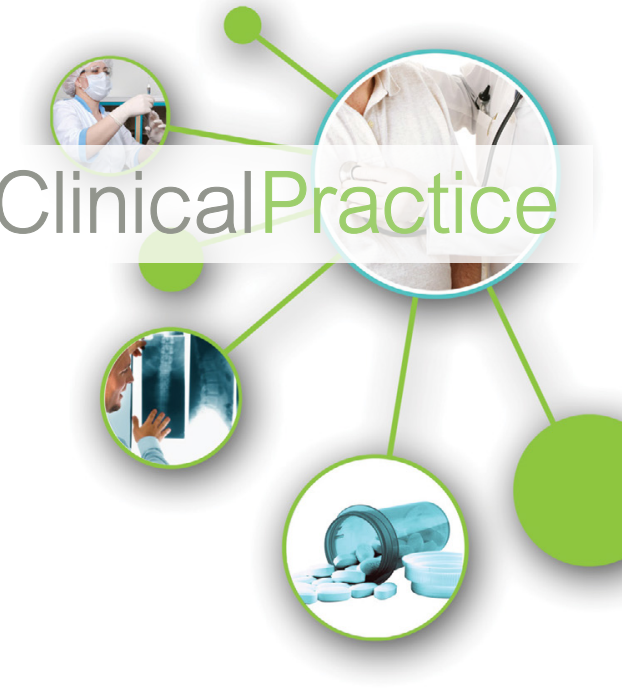

\begin{abstract}
Objectives: To know the patients' satisfaction undergoing thread facelift using FACE-Q.

Materials and Methods: The study was conducted in a private cosmetic surgery setup in patients undergoing thread facelift. Six different scales of FACE-Q questionnaire were used pre-operatively and after 3 months. All the responses were collected. And the data was analyzed to find out the statistical significance.
\end{abstract}

Results: The FACE-Q was completed by 50 patients. All the patients underwent thread facelift which included barbed sutures and PDO threads. The mean age of the patients was 37.7 years (males: 39.3 years and females: 36.8 years). The patients showed significant changes in the pre-operative and postoperative parameters $(p<0.01)$.

Conclusion: The patient-reported outcome instruments like FACE-Q have great implications for ascertaining the outcomes of the cosmetic procedures.

\section{Keywords: FACE-Q, surgery, thread facelift}

\section{Introduction}

The face is the main areas by which individuals present themselves and interact [1]. As the age advances, significant body changes are observed especially in the face $[2,3]$. The demand for cosmetic surgical procedures has increased over the last few years [4]. These changes have been reported with the use of patient-reported outcome instruments to measure the overall quality of life [5].

The FACE-Q was developed which consists of a range of separate scales to measure outcomes after the facial aesthetic procedures [5]. The facial aesthetic procedures are either surgical or minimal-invasive surgical or non-surgical. With the increase in the total number of non-surgical and minimally-invasive surgical procedures, the outcome of this procedure needs to be measured. The FACE-Q provides an opportunity to measure the subjective well-being of the patient. The thread facelift has become one of the commonest minimally invasive cosmetic surgery procedures. There are various kinds of threads available in the market which is absorbable or non-absorbable in nature. These threads include
PDO threads, barbed sutures, Aptos sutures, elastic sutures (Serdev), cogs and cones etc [6-9].

In the current study, the analysis of 50 patients undergoing thread facelift using FACE-Q was analyzed.

\section{Materials and Methods}

The study was conducted in a private cosmetic surgery set up. Only the patients undergoing the thread facelift were included. Patients undergoing a surgical facelift or nonsurgical procedures (like Botox, fillers, fat transfer etc) were excluded. The patients' data was collected. Informed consent was taken from all the patients. Different scales of FACE-Q questionnaire were used which are as follows:

- Satisfaction with facial appearance

- Satisfaction with skin

- Patient-perceived age visual analog scale

- Aging appraisal

- Appearance-related psychological distress

- Satisfaction with outcome

\section{Muhammad Ahmad*}

Aesthetic Plastic Surgery and Hair Transplant Institute, Islamabad, Pakistan

*Author for correspondence:

plasticsurgeonpk@yahoo.com 
All the patients were asked to rate the above-mentioned parameters on the day of the surgery. All the procedure were undertaken under local anesthesia as day-case surgery. After the procedure, the patients have prescribed the first generation of cephalosporin for five days and mild analgesics. All the patients were given necessary precautions.

After 3 months, the patients were asked to rate their responses about the same parameters. All the responses were collected. And the data was analyzed to find out the statistical significance, using Mann-Whitney's U-test using software (Stats tester, version 3.0.1 (code 71) (C), 20162018, BMP group, Saitama, Japan).

\section{Results}

The FACE-Q was completed by 50 patients over a period of 3 years. All the patients underwent thread facelift which included barbed sutures and PDO threads (FIGURE 1). In all the patients, absorbable threads/sutures were used. There were 32 females and 18 males. The mean age of the patients was 37.7 years (males: 39.3 years and females: 36.8 years). The patients' age ranged from 30 to 49 years (male; 32-48 years and females; $30-49$ years).

\section{Satisfaction with facial appearance}

The score increased from 27 to 32 which corresponded from $53 \%$ to $66 \%(\mathrm{p}<0.01)$. The score increased from $49.5 \%$ to $66 \%$ (25.5 to $32.1)$ in males whereas it increased from $55 \%$ to $66 \%(27.8$ to 31.9$)$ in females $(\mathrm{p}<0.01)$.

\section{Satisfaction with skin}

The satisfaction with the facial skin score increased from 29.5 to 33.7 which corresponded to $50 \%$ to $59 \%$ respectively $(\mathrm{p}<0.01)$. The score increased from $50 \%$ to $55 \%$ (29.4 to 31.8 ) in males and $50 \%$ to $61 \%(29.6$ to 34.8$)$ in females $(\mathrm{p}<0.01)$.

\section{Patient-perceived age visual analogue scale}

The patients reported about their perceived age to be 3.4 years older to their present looks. After the procedure, the patients reported looking 4.8 years younger. Therefore, the net gain in the looks was 8.2 years. The perceived age in males was 3.4 years older which changed to 4.5 years younger (7.9 years total gain in looks). In females, the perceived age was 3.4 years older which changed to 4.9 years younger (8.3 years total gain in looks) $(\mathrm{p}<0.01)$.

\section{Aging appraisal}

The aging appraisal about the present looks improved from $45 \%$ to $58 \%$ (15.7 to 19.4 ) $(\mathrm{p}<0.01)$. In males, the aging appraisal improved

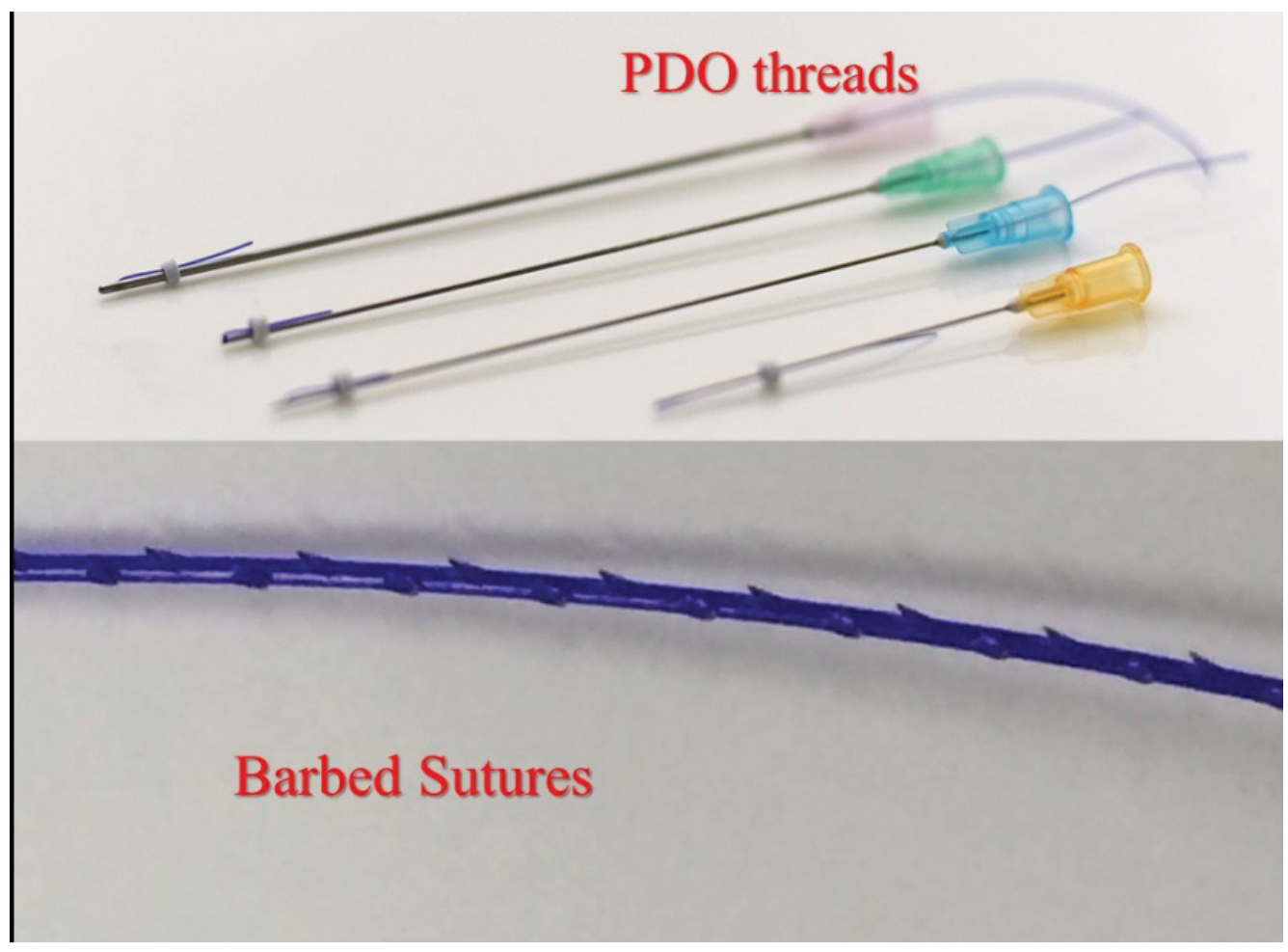

FIGURE 1. PDO and Barbed sutures. 
from $46 \%$ to $58 \%$ (15.9 to 19.4$)$ whereas, in females, the score improved from $44 \%$ to $58 \%$ $(15.6$ to 19.4$)(\mathrm{p}<0.01)$.

\section{- Appearance-related psychological distress}

The psychological distress score decreased from 25.4 to 16.8 (65\% to $45 \%)(\mathrm{p}<0.01)$. the score in males decreased from $65 \%$ to $42 \%$ (25.4 to 16.1$)$ whereas, in females, the scores decreased from $65 \%$ to $46 \%$ (25.4 to 17.2 ) $(\mathrm{p}<0.01)$.

\section{- Satisfaction with outcome}

The overall satisfaction rate with outcome was $20.1(68 \%)$. The satisfaction rate in males was $18.1(59 \%)$ and $21.2(73 \%)$ in females $(\mathrm{p}<0.01)$.

\section{Discussion}

The minimally invasive techniques are being accepted by the people and surgeons very easily and the practice of these procedures is increasing. The thread facelift is one of the minimally invasive cosmetic procedures which results in an immediate change in facial profile and has low downtime for recovery. These innovations result in high patient satisfaction and less operative and postoperative morbidity [10]. There are various kinds of threads which are used in thread facelift. These absorbable and nonabsorbable sutures [11]. The absorbable sutures include polydioxanone (PDO), Silhouette soft (poly-l-lactate), or bidirectional cones. The non- absorbable sutures include APTOS, Contour threads, Waffles threads (polypropylene). These threads may be barbed or non-barbed, unidirectional or bidirectional.

The documentation of these thread facelift procedures is very important. There are various methods to measure the satisfaction but the Patient-Reported Outcome (PRO) instruments are being used widely worldwide in clinical practice. After the development of FACE-Q by Cano and Klassen et al., in the early 2000s, it is being widely accepted and used in clinical studies to document the pre and postoperative outcome in patients undergoing facial procedures. The FACE-Q consists of many items which encompass various areas and aspects [12]. The current study is first of its kind which documents the results of FACE-Q used after thread facelift in Pakistani population (FIGURE 2). The mean age of the patients was 39.3 years in the current series which is different in few other studies $[13,14]$. As the patients underwent midface lift, therefore we included only six parameters. In these patients, the overall improvement in facial appearance was 66\% postoperatively and the satisfaction with the skin was $59 \%$ which is similar to the satisfaction rate in other studies $[15,16]$. FACE-Q provides a reliable instrument to document any change perceived by the patient after the procedure. The different modules and questions help to rate the different aspects of the physical and psychological improvement. The changes
FIGURE 2. Pre and post-operative result of threadlift.

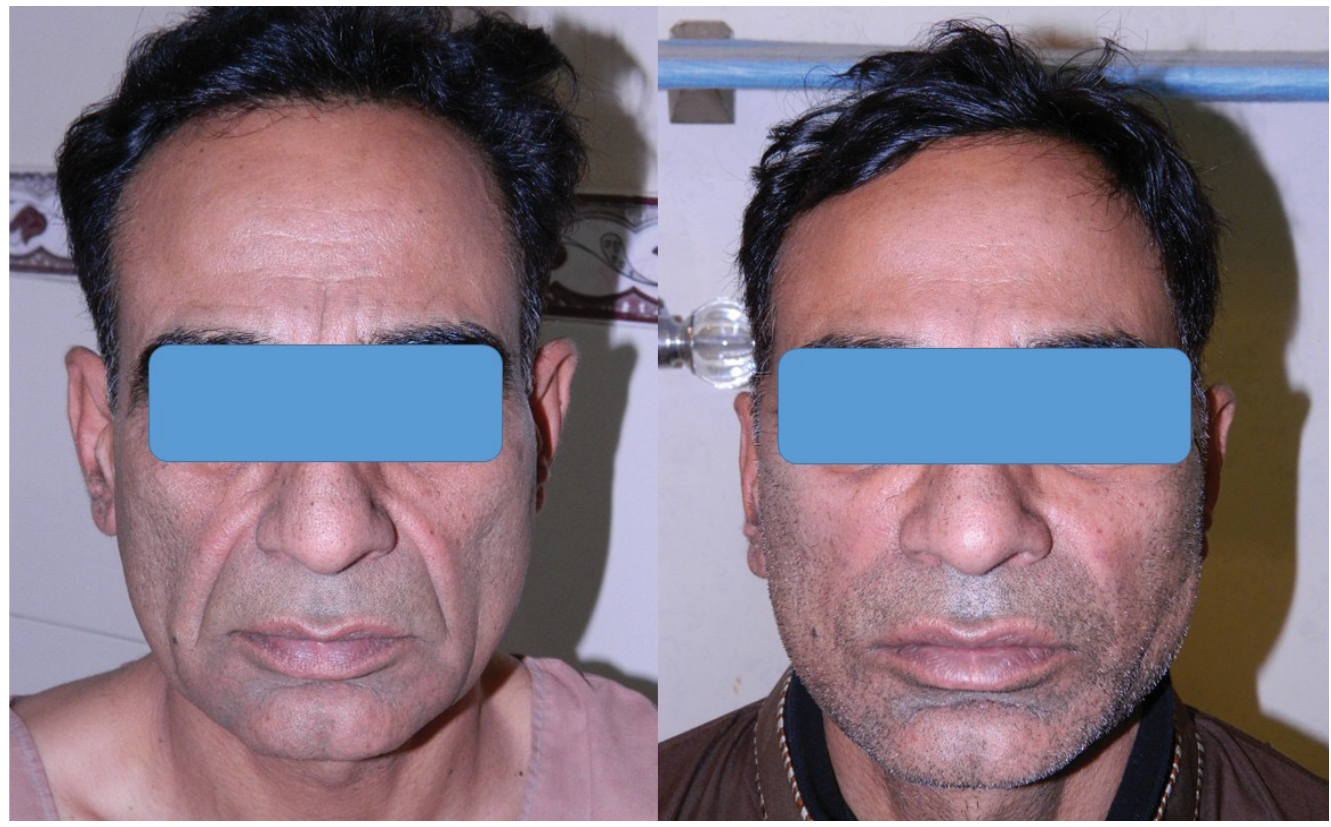




\begin{tabular}{|c|c|c|c|c|c|c|c|c|c|c|c|c|}
\hline \multirow{2}{*}{ FACE-Q items } & \multicolumn{4}{|c|}{ Total } & \multicolumn{4}{|c|}{ Male } & \multicolumn{4}{|c|}{ Females } \\
\hline & Before & $\%$ & After & $\%$ & Before & $\%$ & After & $\%$ & Before & $\%$ & After & $\%$ \\
\hline$A$ & 27 & 53 & 32 & 66 & 25.5 & 49.5 & 32.1 & 66 & 27.8 & 55 & 31.9 & 66 \\
\hline$B$ & 29.5 & 50 & 33.7 & 59 & 29.4 & 50 & 31.8 & 55 & 29.6 & 50 & 34.8 & 61 \\
\hline$C$ & 3.4 & - & 1.3 & - & 3.4 & - & 1.2 & - & 3.4 & - & 1.3 & - \\
\hline$D$ & 15.7 & 45 & 19.4 & 58 & 15.9 & 46 & 19.4 & 58 & 15.6 & 44 & 19.4 & 58 \\
\hline E & 25.4 & 65 & 16.8 & 45 & 25.4 & 65 & 16.1 & 42 & 25.4 & 65 & 17.2 & 45 \\
\hline $\mathrm{F}$ & - & - & 20.1 & 68 & - & - & 18.1 & 59 & - & - & 21.2 & 73 \\
\hline
\end{tabular}

observed are documented and compared with the preoperative scores. Although FACE-Q is a patient-reported questionnaire, it can also be used as an observer-based instrument as well (TABLE 1).

\section{Conclusion}

FACE-Q provides a very important tool in patients' evaluation after thread lift. 


\section{References}

Cole J. Empathy needs a face. J. Consciousness Stud. 8, 51-68 (2001).

Honigman R, Castle DJ. Aging and cosmetic enhancement. Clin. Invest. Aging. 1(2), 115-119 (2006).

Finn CJ, Cox SE, Earl ML. Social implications of hyper-functional facial lines. Dermatol. Surg. 29(5), 450-455 (2003).

https://www.plasticsurgery.org/ documents/News/Statistics/2017/plasticsurgery-statistics-report-2017.pdf

Klassen AF, Canno SJ, Schwitzer JA, et al. Development and psychometric validation of FACE-Q skin, lips and facial rhytides appearance scales and adverse effect checklists for cosmetic procedures. JAMA Dermatol. 152(4), 443-451 (2016).

de Benito J, Pizzamiglio R, Theodorou D, Arvas L. Facial rejuvenation and improvement of malar projection using sutures with absorbable cones: surgical technique and case series. Aesthetic Plast. Surg. 35(2), 248-253 (2011).

Matarasso A. Introduction to the barbed sutures supplement: The expanding applications of barbed sutures. Aesthet. Surg. J. 33(3 Suppl), 7S-11S (2013).

Sulamanidze M, Sulamanidze G. APTOS suture lifting methods: 10 years of experience. Clin. Plast. Surg. 36(2), 281-306 (2009).

Serdev N, eds. Mini-invasive face and body lifts: closed suture lifts or barbed thread lifts. IntechOpen publishers 2013.

Hibler BP, Schwitzer J, Rossi AM. Assessing improvement of facial appearance and quality of life after minimally-invasive cosmetic dermatology procedures using the FACE-Q scales. J. Drugs Dermatol. 15(1), 62-67 (2016).

Yongtrakul P, Sirithanabadeekul P, Siriphan P. Thread lift classification, technique, and how to approach the patient. Int. J. Med. Health Sci. 10912,
547-555 (2016).

http://www.eprovide.mapi.trust.org/ instruments/face-q

Qureshi AA, Parikh PP, Sharma K, et al. Nonsurgical facial rejuvenation: outcome and safety of neuromodulator and soft tissue filler procedures performed in a resident cosmetic clinic. Aesthet. Plast. Surg.41(5), 1177-1183 (2017).

Kappos EA, Temp M, Schafer DJ, Haug M, Kalbermatten DF. Validating facial aesthetic surgery results with the FACE-Q. Plast. Reconstr. Surg. 139(4), 839-845 (2017).

Sinno S, Schwitzer J, Anzai L, Thorne $\mathrm{CH}$. Facelift satisfaction using the FACE-Q. Plast. Reconstr. Surg. 136(2), 239-242 (2015).

Rossi A, Hibler B, Schwitzer J, Pusic AL. Assessing improvement of facial appearance and quality of life in cosmetic surgery patients using the FACE-Q scales. Aesthet. Surg. J. 35(7), 784-793 (2015). 